
ГИПЕРБИЛИРУБИНЕМИЯ (СОЧЕТАНИЕ СИНДРОМА КРИГЛЕРА-НАЙЯРА ІІ ТИПА И СИНДРОМА ЖИЛЬБЕРА) 1,2Л. Ю. Ильченко, ${ }^{1,3}$ И. Г. Федоров, ${ }^{1}$ Г. Г. Тотолян, ${ }^{3}$ А. Г. Цветкова, ${ }^{1}$ Е. Г. Гавриленко, ${ }^{4}$ К. О. Миронов, ${ }^{1,5}$ И. Г. Никитин

${ }^{1}$ Российский национальный исследовательский медицинский университет имени Н.И. Пирогова Минздрава России, Москва, Российская Федерация ${ }^{2}$ Федеральный научный центр исследований и разработки иммунобиологических препаратов имени М. П. Чумакова РАН, Москва, Российская Федерация ${ }^{3}$ Городская клиническая больница имени В. М. Буянова Департамента здравоохранения е. Москвы, Москва, Российская Федерация ${ }^{4}$ Центральный научно-исследовательский институт эпидемиологии Роспотребнадзора, Москва, Российская Федерация 5Лечебно-реабилитационный центр Минздрава России, Москва, Российская Федерация

Введение. Энзимопатические желтухи проявляются перемежающейся гипербилирубинемией при отсутствии изменений структуры печени, гемолиза, резус-конфрликта и холестаза. К ним относят синдром Криглера-Найяра I типа, синдром Криглера-Найяра II типа и синдром Жильбера (СЖ). Они характеризуются аутосомно-рецессивным типом наследования вследствие возникновения мутаций и полиморфизмов гена билирубин-уридин-5'-дифросфратәлюкуронозилтрансфреразы (UGT1A1), что приводит к снижению активности фрермента либо к полной ее потере.

Цель исследования - демонстрация особенностей диагностики и лечения редкого случая наследственной неконъюгированной гипербилирубинемии - сочетания синдрома Криглера-Найяра II типа и синдрома жильбера.

Материал и методы. Данные клинического наблюдения пациента Г., 19 лет, находившегося на обследовании и лечении в отделении гастроэнтерологии многопрофильного стационара г. Москвы в январе 2021 г.

Результаты. У пациента Г. с рождения отмечается желтушность склер и кожных покровов; периодами беспокоит быстрая утомляемость, общая слабость. При фризикальном осмотре изменений (за исключением желтушной окраски) не выявлено. Среди лабораторных показателей зарегистрировано лишь повышение уровня неконъюгированного билирубина, который достигал 270 мкмоль/л (медиана - 170 мкмоль/л). При молекулярно-генетическом исследовании UGT1A1 выявлены мутации в 4 экзоне Val378Asp (2002) u Arg108Cys, в промоторном регионе - полиморфизм 6/7TA, что подтверждает аутосомно-рецессивное наследственное заболевание - сочетание синдрома Криглера-Найяра 2 типа и синдрома Жильбера (гетерозиготное состояние), осложнившееся развитием печёночной энцефралопатии 2 степени. На фроне приема индуктора микросомальных фрерментов (френобарбитала) и корректора гипераммониемии (орнитин-аспартата) отмечено достоверное снижение уровня неконъюгированного билирубина до 170,5 мкмоль/л, а также улучшение общего состояния - уменьшение утомляемости, слабости.

Выводы. Применение молекулярно-генетического анализа позволяет строго индивидуально выстраивать стратегию диагностики, лечения и профилактики заболевания. Сохранению удовлетворительного уровня качества жизни способствует исключение неблагоприятных воздействий, провоцирующих развитие данного синдрома, и контроль фракторов риска.

Ключевые слова: синдром Криглера-Найяра II типа; синдром Жильбера; неконъюгированная гипербилирубинемия; ген уридин-5'-дифосфрат (UDP) -глюкуронозилтрансфреразы.

\title{
HEREDITARY UNCONJUGATED HYPERBILIRUBINEMIA (COMBINATION OF CRIGLER-NAJJAR SYNDROME TYPE II AND
} GILBERT'S SYNDROME)

1,2L. Yu. Ilchenko, ${ }^{1,3}$. G. Fedorov, ${ }^{1}$ G. G. Totolyan, ${ }^{2}$ A. G. Tsvetkova, ${ }^{1}$ E. G. Gavrilenko, ${ }^{4} \mathrm{~K}$. O. Mironov, ${ }^{1,5}$. G. Nikitin ${ }^{1}$ Pirogov Russian National Research Medical University, Moscow, Russian Federation ${ }^{2}$ Chumakov Federal Scientific Center for Research and Development of Immune-and-Biological

Products, Moscow, Russian Federation

${ }^{3}$ Moscow City Clinical Hospital after V.M. Buyanov; Moscow, Russian Federation ${ }^{4}$ Central Research Institute of Epidemiology of the Federal Service on Customers' Rights Protection and Human Well-being Surveillance, Moscow, Russian Federation

${ }^{5}$ Centre of Medical Rehabilitation; Moscow, Russian Federation 
Background. Enzymopathic jaundices are manifested by intermittent hyperbilirubinemia, no changes in the structure of the liver, no hemolysis, Rh-conflict as well as cholestasis being noted. These jaundices include Crigler-Najjar syndrome type I, Crigler-Najjar syndrome type II and Gilbert's syndrome. They are characterized by an autosomal recessive inheritance due to the presence of mutations and polymorphisms in uridine 5'-diphosphate-glucuronosyltransferase gene (UGT1A1) leading to a decrease of the enzyme activity or to its complete loss.

Objective. To demonstrate the peculiarities of diagnosis and treatment of a rare case of hereditary unconjugated hyperbilirubinemia - a combination of Crigler-Najjar syndrome type II and Gilbert's syndrome.

Material and methods. Clinical observation of a patient G. aged 19, who was examined and treated at the Department of gastroenterology of a multidisciplinary hospital in Moscow in January 2021.

Results. The patient $\mathrm{G}$. has had icteric sclerae and skin since birth; he occasionally suffers from easy fatigability and general malaise. Physical examination revealed no changes (except for icteric discoloration). An increase in unconjugated bilirubin up to $270 \mu \mathrm{mol} / \mathrm{L}$ (median - $170 \mu \mathrm{mol} / \mathrm{L}$ ) was detected. The molecular genetic study of UGT1A1 gene identified mutations in exon 4 Val378Asp (2002) and Arg108Cys as well as polymorphism 6/7TA in the promoter region, confirming the diagnosis of autosomal recessive inherited disease - a combination of Crigler-Najjar syndrome type II and Gilbert's syndrome (heterozygous state), complicated by the development of hepatic encephalopathy stage 2. There was noted a significant decrease in unconjugated bilirubin up to $170.5 \mu \mathrm{mol} / \mathrm{L}$, as well as improvement in general condition - reduced fatigue and weakness during the treatment with microsomal enzyme inducer (phenobarbital) and hyperammonemia corrector (ornithine aspartate).

Conclusions. The use of molecular genetic analysis allows tailoring strategies for patient-specific disease diagnostics, treatment and prevention. The preservation of quality of life within satisfactory level is achieved through elimination of adverse effects provoking the development of this syndrome and through control of risk factors.

Keywords: Crigler-Nayyar syndrome type II; Gilbert's syndrome; unconjugated hyperbilirubinemia; uridine 5'-diphosphate (UDP)-glucuronosyltransferase gene.

\section{Автор, ответственный за переписку:}

Ильченко Людмила Юрьевна, д-р мед. наук, профессор; Российский национальный исследовательский медицинский университет имени Н. И. Пирогова;

e-mail: ilchenko-med@yandex.ru

Для цитирования: Наследственная неконъюгированная гипербилирубинемия (сочетание синдрома Криглера-Найяра II типа и синдрома Жильбера) / Л. Ю. Ильченко, И. Г. Федоров, Г. Г. Тотолян, А. Г. Цветкова, Е. Г. Гавриленко, К. О. Миронов И. Г. Никитин // Гепатология и гастроэнтерология. 2021. Т. 5 №1.C. 79-84.https://doi.org/10.25298/2616-5546-2021-5-1-79-84

\section{Введение}

При заболеваниях печени энзимопатические желтухи, проявляющиеся неконъюгированной гипербилирубинемией (НГ), занимают особое место. К ним относят синдром Криглера-Найяра I типа (синдром К-Н I), синдром Криглера-Найяра II типа (синдром К-Н I) и синдром Жильбера (СЖ).

Данные синдромы характеризуются аутосомно-рецессивным типом наследования, обусловлены нарушением обмена билирубина и проявляются хронической или перемежающейся желтухой без выраженного изменения структуры печени, явных признаков повышенного гемолиза, резус-конфрликта и холестаза. Однако помимо желтушного окрашивания склер и кожи могут наблюдаться нарушения центральной нервной системы, провоцируемые токсическим воздействием патологически высоких концентраций неконъюгированного билирубина (НБ), в частности при синдроме К-Н I [1].

Общим для них является наличие мутаций гена билирубин-уридин-5'-дифосфатглюкуронозилтрансферазы (uridine 5'-diphosphateglucuronosyltran-ferase gene - UGT1A1). Ген UGT1A1 кодирует уридин-дифосфратглюкуронозилтрансферазу (УДФГТ) - фермент второй

\section{Corresponding author:}

Ilchenko Lyudmila Yu., PhD, MD (Medicine), professor; Pirogov Russian national research medical university: e-mail: ilchenko-med@yandex.ru

For citation: Ilchenko LYu, Fedorov IG, Totolyan GG, Tsvetkova AG, Gavrilenko EG, Mironov KO, Nikitin IG. Hereditary unconjugated hyperbilirubinemia (combination of Crigler-Nayyar syndrome type II and Gilbert's syndrome). Hepatology and Gastroenterology. 2021;5(1):79-84. https://doi. org/10.25298/2616-5546-2021-5-1-79-84

фазы метаболизма ксенобиотиков, который осуществляет реакцию конъюгирования разных соединений с глюкуроновой кислотой $[2,3]$.

Синдром К-H I характеризуется практически полным отсутствием УДФГТ в печени. Это редко встречающееся заболевание - 0,6-1 случай на 1 млн населения. Содержание НБ может достигать 800-850 мкмоль/л. Имеет злокачественное прогрессирующее течение с летальным исходом в раннем возрасте при отсутствии трансплантации печени [4].

При синдроме К-Н II активность УДФГТ составляет менее 20-30\% от нормальной; НБ может повышаться до 300-350 мкмоль/л. Продолжительность жизни пациентов при естественном течении заболевания достигает 45-50 лет.

СЖ отличается благоприятным течением [5]. Распространенность СЖ среди взрослого населения в мире вариабельна: в европейской популяции частота СЖ составляет 5-10\% [6], среди амбулаторных пациентов в г. Москве - 24\% [7]. Уровень НБ, как правило, не превышает 85-90 мкмоль/л, что вызвано нерезким снижением активности УДФГТ. Продолжительность жизни пациентов с СЖ не ниже, чем у здоровых лиц.

При наличии двух синдромов - К-Н II и СЖ, обусловленных комбинацией мутаций в UGT1A1, 
у части пациентов наблюдается промежуточная концентрация НБ [8]. При этом весьма сложно по клинической картине провести четкое разграничение между данными патологическими состояниями.

Цель исследования - демонстрация особенностей диагностики и лечения редкого случая наследственной неконъюгированной гипербилирубинемии - сочетания синдрома Криглера-Найяра II типа и синдрома Жильбера.

\section{Материал и методы}

Представлены данные клинического наблюдения пациента Г., 19 лет, находившегося на обследовании и лечении в отделении гастроэнтерологии многопрофильного стационара г. Москвы в январе 2021 г.

\section{Результаты и обсуждение}

Пациент Г., 19 лет, госпитализирован в отделение гастроэнтерологии многопрофильного стационара с жалобами на желтушность склер и кожных покровов, быструю утомляемость, общую слабость.

У Г. с рождения отмечалась желтушность склер и кожи. Мальчик родился в срок от первой нормальной беременности. Уровень НБ у новорожденного достигал 250 мкмоль/л, показатель конъюгированного билирубина оставался нормальным (4 мколь/л). В процессе обследования были исключены желтуха новорожденных, гемолиз, резус-конфликт, групповая несовместимость и другие причины, способные вызвать гипербилирубинемию. В связи с сохраняющейся желтухой для исключения наследственной гипербилирубинемии ребенку на первом году жизни было проведено молекулярно-генетическое исследование (2002 г.) гена UGT1A1, выявившее в 4 экзоне мутацию V378D (замена в 378 положении валина на аспарагиновую кислоту), а также увеличение в промоторной зоне ТА-повторов (в первоначальном заключении отсутствовала количественная оценка инсерций ТА).

В этот же период времени при обследовании отца установлено, что он является гетерозиготным носителем мутации V378D, а у матери пациента, согласно представленным данным, зарегистрировано увеличение ТА-повторов в промоторной зоне гена UGT1A1 в гетерозиготном состоянии. При этом у обоих родителей содержание билирубина никогда не превышало референсного значения.

При повторном молекулярно-генетическом исследовании (2013 г.) у пациента и его матери в 4 экзоне гена UGT1A1 обнаружена дополнительная (к выявленной ранее) мутация R108C (замена в 108 положении аргинина на цистеин).

При анализе анамнеза заболевания установлено, что уровень НБ у Г. максимально достигал
270 мкмоль/л (медиана - 170 мкмоль/л). Периодически его беспокоила слабость, утомляемость после фризических или эмоциональных нагрузок. Пациент постоянно принимал препараты УДХК в дозе 250 мг/сутки.

Окончив школу, Г. поступил в университет. Знает три языка, прекрасно рисует. После года учебы на фоне снижения общей активности и увеличения утомляемости отметил нарастание желтухи. При контрольном исследовании зарегистрировано повышение уровня НБ до 258 мкмоль/л. Остальные биохимические показатели были не изменены. По данным фиброэластографии, плотность печени соответствовала нормальным значениям (F0 по METAVIR). Направлен в стационар для обследования и лечения.

При поступлении в отделение состояние пациента Г. расценивалось как удовлетворительное. Индекс массы тела - 18,5 кг/м². Из патологических проявлений наблюдалась лишь интенсивная желтушность склер и кожных покровов. Других изменений при фризикальном осмотре не выявлено.

При анализе родословной пациента, включающей 4 поколения, не было получено данных о наличии каких-либо клинических проявлений генетического заболевания у родственников. У пробанда есть младший (на три года) здоровый брат.

Поскольку выраженная НГ может приводить к развитию токсического повреждения мозга и вызывать энцефалопатию, Г. был проведен тест связи чисел. Время выполнения теста составило 95 с (рис. 1), что соответствует печёночной энцефалопатии (ПЭ) 2 ст.

Клинические анализы крови (включая ретикулоциты) и мочи без отклонений от нормы. В биохимическом анализе крови по-прежнему выявлялась лишь выраженная НГ (213,2 мкмоль/л). Реакция Кумбса отрицательная. Маркеры вирусов гепатитов В и C - отрицательные. Гормоны щитовидной железы в норме. Зарегистрировано повышение уровня аммиака (121 мкмоль/л) в капиллярной крови (норма до 54 мкмоль/л).

При ультразвуковом исследовании (УЗИ) органов брюшной полости патологических изменений печени, желчного пузыря, селезёнки не обнаружено.

По данным эзофрагогастродуоденоскопии (ЭГДС) впервые выявлена умеренная деформация луковицы двенадцатиперстной кишки, отмечен также плоский постъязвенный рубец (до 4 мм) по передне-нижней стенке за привратником. Уреазный тест на наличие Helicobacter pylori (Hр) положительный.

С целью уточнения изменений в промоторной зоне UGT1A1 выполнено молекулярно-ге- 


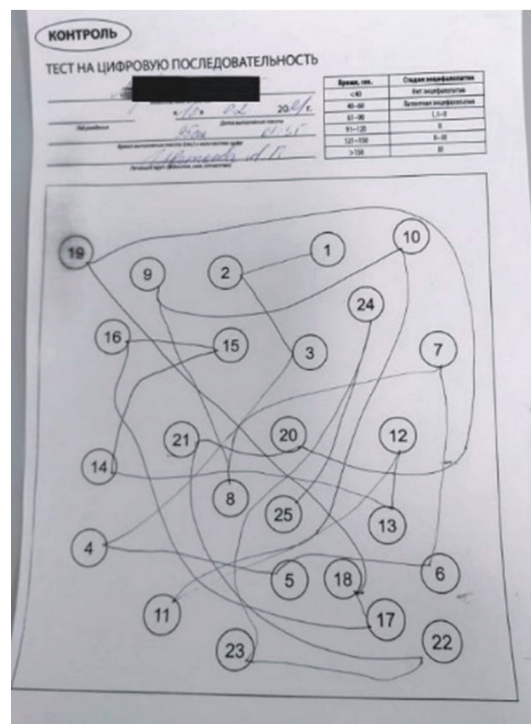

Рисунок 1. - Тест связи чисел пациента Г. Figure 1. - Number connection test of patient $G$.

нетическое исследование (2021 г.). Выделена ДНК, проведены полимеразная цепная реакция и секвенирование с использованием набора реагентов «АмплиСенс® Пироскрин UGT1A1-скрин» производства ФБУН Центрального НИИ Эпидемиологии (регистрационное удостоверение № Р3Н 2016/4339 от 28.06.2016) [9]. Определен полиморфизм rs8175347 в гетерозиготном coстоянии - выявлен генотип (ТА)6/(ТА)7 (рис. 2).

В таблице представлены имеющиеся суммарные результаты молекулярно-генетического исследования.

Пациенту установлен диагноз: наследственная неконъюгированная гипербилирубинемия: сочетание синдрома Криглера-Найяра II типа и синдрома Жильбера (полиморфизм rs8175347 в гетерозиготном состоянии). Печёночная энцефралопатия 2 степени. Язвенная болезнь луковицы двенадцатиперстной кишки, Нр+, ремиссия.

Для снижения уровня НБ пациенту рекомендован прием индуктора микросомальных фрерментов - фенобарбитал 0,1 г/сут в течение 7 дней, с целью купирования клинических проявлений энцефралопатии и коррекции гиперам-

\section{C6: ATATAT[AT]GGCAAAAACCAA}

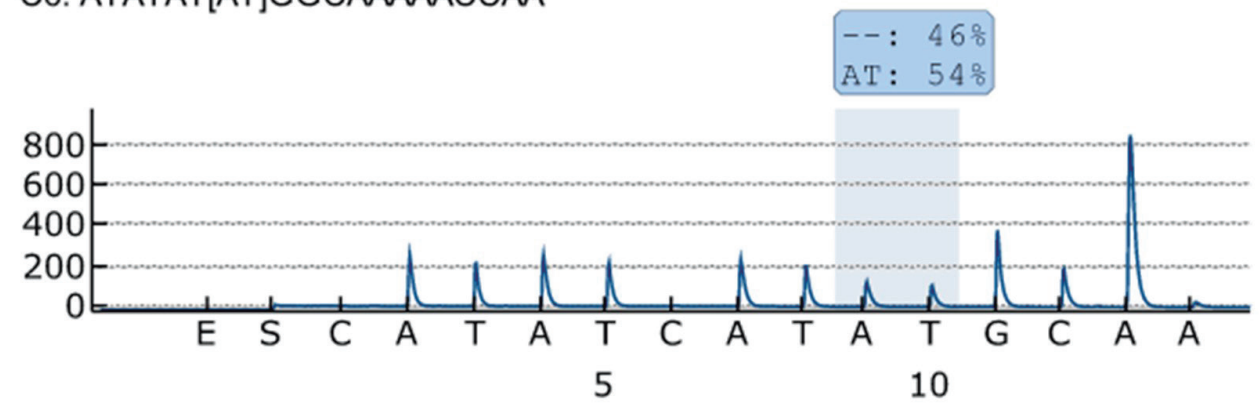

Рисунок 2. - Нуклеотидная последовательность фрагмента гена UGT1A1 у пациента Г. с детекцией полиморфизма rs8175347 в гетерозиготном состоянии

Figure 2. - Detection of rs8175347 heterozygote genotype in patient's G. DNA sample
Таблица. - Результаты генетического исследования пациента Г. и его родителей (2002-2021 гг.)

Table. - Results of the genetic study of the patient and his parents (2002-2021)

\begin{tabular}{|l|c|c|}
\hline $\begin{array}{c}\text { Обследуемый } \\
\text { Patients }\end{array}$ & $\begin{array}{c}\text { UGT1A1, } \\
\text { промоторная обл. } \\
\text { UGT1A1, promoter } \\
\text { region }\end{array}$ & $\begin{array}{c}\text { UGT1A1, 4 экзон } \\
\text { UGT1A1, 4 ехоn }\end{array}$ \\
\hline $\begin{array}{l}\text { Г. } \\
\text { G. }\end{array}$ & $\begin{array}{c}\text { Нет данных } \\
\text { nо data }\end{array}$ & V378D (2002) \\
\hline $\begin{array}{l}\text { Oтец } \\
\text { Father }\end{array}$ & $\begin{array}{l}\text { Увеличение TA- } \\
\text { R108C (2013) }\end{array}$ \\
\hline $\begin{array}{l}\text { Maть } \\
\text { Mother }\end{array}$ & Arg108Cys (2013) \\
\hline
\end{tabular}

мониемии - орнитин-аспартат в дозе 9,0 г/сут длительно. С учетом положительного уреазного теста назначен пробиотик Pylopass (Lactobacillus reuteri) по 1 капсуле/сутки. От эрадикационной терапии Нр было решено воздержаться в связи с выраженной гипербилирубинемией и вероятностью развития нежелательных явлений при применении антибиотиков. Продолжен прием УДХК с целью профилактики желчнокаменной болезни (ЖКБ).

На фроне терапии отмечено достоверное снижение НБ - до 170,5 мкмоль/л, а также улучшение общего состояния - уменьшение утомляемости, слабости.

Как известно, наследственные НГ связаны с нарушениями регуляции экспрессии или активности фермента UGT1A1, который является частью локуса UGT1A, кодирующего семейство ферментов UGT [10].

UGT1A кодирует 9 разных представителей семейства UGT1A (UGT1A1 и UGT1A3 - UGT1A10). Наиболее изучен фермент UGT1A1, экспрессируемый в желудке, печени и кишечнике [11].

Данный фрермент играет ключевую роль в выведении из организма билирубина - продукта распада гема, катализирует превращение липофильного НБ в конъюгированный, который растворяется в воде и легко выводится с желчью. Нарушение процесса конъюгации при гипербилирубинемии приводит к накоплению НБ, который проникает в митохондрии, где разобщает дыхание и окислительное фоссрорилирование, изменяет синтез белка, функционирование калий-натриевого насоса, что отрицательно сказывается на состоянии центральной нервной системы, вызы- 
вает неврологические симптомы, токсическую энцефалопатию.

Мутации и генетические полиморфизмы гена UGT1A1 могут приводить к снижению активности фермента либо к полной потере мутации вследствие замены аминокислот, приводят к полиморфизмам гена UGT1A1, что обуславливает снижение активности фермента либо полную ее потерю [4, 12].

В настоящее время выявлено более 113 мутаций, вызывающих СЖ и синдром К-Н [13]. Полиморфизм rs8175347 в промоторе UGT1A1 - частый генетический вариант, влияющий на функцию фермента. (TA)7 (UGT1A1*28) и (TA)6 (UGT1A1*1) - наиболее частые аллели во всех изученных на сегодняшний день популяциях, в отличие от более редких аллелей (TA)8(UGT1A1*37) и (TA)5 (UGT1A1*36).

Генетические исследования гена UGT1A1 привели к открытию значительного числа мутаций в его разных экзонах у пациентов с синдромом К-Н I и II типов [12-14].

Японские авторы Y. Maruo и et. al, 2016 г. [8] обследовали 99 мужчин и 64 женщин с НГ (содержание билирубина колебалось от 20 мкмоль/л до 379 мкмоль/л). Генетический анализ UGT1A1 был выполнен с помощью секвенирования. Изучена связь между концентрацией билирубина в сыворотке крови и выявленными генотипами. Авторы выделили три группы пациентов: с типичным синдромом К-Н II, промежуточную группу с сочетанием синдромов К-Н ІІСЖ и с типичным СЖ. У большинства пациентов определены двуаллельные мутации UGT1A1. Кроме того, многие из них $(78,5 \%)$ имели множественные мутации. Концентрации билирубина в сыво-

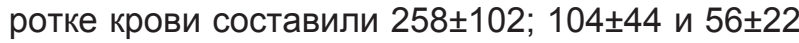
мкмоль/л, соответственно. Данное исследование подтверждает необходимость тщательной оценки и поиска взаимосвязи между генотипами и фенотипом (в частности содержанием билирубина). Кроме того, показано, что мутации UGT1A1 значительно различаются среди этнических групп - у азиатов и кавказоидов [15].

Наследственные НГ относятся к аутосомно-рецессивным заболеваниям, при которых каждая из двух мутантных хромосом содержит разные мутации в анализируемом гене.

Нередко случаи сочетания синдрома К-H II и СЖ обусловлены кровнородственными браками между предположительно гетерозиготами по одной и той же мутации.

В нашем наблюдении у пациента Г. выявлены 2 мутации в 4 экзоне UGT1A1 - V378D (2002) и $\mathrm{R} 108 \mathrm{C}$, наследуемые отдельно от отца и матери, и полиморфизм rs8175347 в гетерозиготном состоянии (генотип (ТА)6/(ТА)7).

\section{Выводы}

Сочетание синдрома К-Н II и СЖ лишь частично охарактеризовано в относительно небольших исследованиях. Нами представлен такой случай наследственной НГ, редко встречающейся в клинической практике.

Применение молекулярно-генетического анализа позволяет строго индивидуально выстраивать стратегию диагностики, лечения и профилактики заболевания.

Среди исходов НГ у пациента Г. следует рассматривать прогрессирование ПЭ и печёночно-клеточной недостаточности, развитие ЖКБ, цирроза печени (встречается редко, вероятно, вторично на фоне ЖКБ и др.). Необходимо учитывать возможность гепатотоксичности, поскольку генетические полиморфизмы UGT1A1 являются критическим фактором при выборе фармакотерапии.

Сохранению удовлетворительного уровня качества жизни способствует исключение неблагоприятных воздействий, провоцирующих развитие данного синдрома, и контроль факторов риска.

Некоторая эфффективность при синдроме К-Н II получена от применения фоототерапии (450460 нм) у новорожденных и индуктора микросомальных ферментов (фенобарбитала) - у взрослых пациентов.

Трансплантация печени может оказаться единственным радикальным методом лечения при прогрессировании печёночно-клеточной недостаточности и ПЭ. Однако она сопряжена с высокими затратами, медицинскими и хирургическими заболеваниями и рисками от иммуносупрессии.

В будущем в лечении фратальных НГ применение генной терапии, CRISPR (Clustered Regularly Interspaced Short Palindromic Repeats - технология редактирования геномов высших организмов) на пренатальном этапе развития человека, вероятно, позволит прогнозировать заболевание и устранять генные мутации.

\section{References}

1. Crigler JF Jr, Najjar VA. Congenital familial nonhemolytic jaundice with kernicterus. Pediatrics. 1952;10(2):169-80.

2. King CD, Rios GR, Green MD, Tephly TR. UDPglucuronosyltransferases. Curr Drug Metab. 2000;1(2):14361. doi: $10.2174 / 1389200003339171$.

3. Beutler E, Gelbart T, Demina A. Racial variability in the UDPglucuronosyltransferase 1 (UGT1A1) promoter: a balanced polymorphism for regulation of bilirubin metabolism? Proc Natl Acad Sci U S A. 1998;95(14):8170-4. doi: 10.1073/ pnas.95.14.8170.
4. Dhawan A, Lawlor MW, Mazariegos GV, McKiernan P, Squires JE, Strauss KA, Gupta D, James E, Prasad S. Disease burden of Crigler-Najjar syndrome: Systematic review and future perspectives. J Gastroenterol Hepatol. 2020;35(4):530-543. doi: 10.1111/jgh.14853.

5. Gilbert NA, Lereboullet P. La cholémie simple familiale. Sem Med. 1901;21:241-243.

6. Wagner KH, Shiels RG, Lang CA, Seyed Khoei N, Bulmer AC. Diagnostic criteria and contributors to Gilbert's 
syndrome. Crit Rev Clin Lab Sci. 2018;55(2):129-139. doi 10.1080/10408363.2018.1428526

7. Melnikova LI, Ilchenko LYu, Dunaeva EA, Kozitsyna MV, Dribnokhodova OP, Mironov KO. Vyjavlenie sindroma Zhilbera metodom pirosekvenirovanija u pacientov v realnoj klinicheskoj praktike [Diagnosis of Gilbert's syndrome via pyrosequencing in clinical practice]. Arhiv vnutrennej mediciny [The Russian Archives of Internal Medicine]. 2019;9(6):475-482. doi: 10.20514/2226-6704-2019-9-6475-482. (Russian).

8. Maruo $Y$, Nakahara S, Yanagi $T$, Nomura A, Mimura $Y$ Matsui K, Sato H, Takeuchi Y. Genotype of UGT1A1 and phenotype correlation between Crigler-Naijar syndrome type II and Gilbert syndrome. J Gastroenterol Hepatol. 2016;31(2):403-8. doi: 10.1111/jgh.13071.

9. Dribnokhodova OP, Mironov KO, Dunaeva EA, Shipulin GA. Opredelenie polimorfizma (TA)6/(TA)7 v gene UGT1A1 metodom pirosekvenirovanija [A pyrosequencingbased method for the detection of UGT1A1 (TA)6/(TA)7 polymorphism]. Molekulyarnaya meditsina [Molecular medicine]. 2014;(2):38-40. (Russian).

10. Liang C, Luo L, Bai J, Bai L, Bian DD, Ren Y, Liu S, Chen Y, Duan ZP, Zheng SJ. [Analysis of mutation site characteristics of Gilbert syndrome and Crigler--Najiar syndrome in relation to uridine diphosphate glucuronosyltransferase A1 gene] Zhonghua Gan Zang Bing Za Zhi. 2020;28(5):428-433. doi: 10.3760/cma.j.cn501113-20200217-00051. (Chinese).

11. Strassburg CP, Kneip S, Topp J, Obermayer-Straub P, Barut A, Tukey RH, Manns MP. Polymorphic

Конфрликт интересов. Авторы заявляют об отсутствии конорликта интересов.

Финансирование. Исследование проведено без спонсорской поддержки.

Соответствие принципам этики. Исследование одобрено локальным этическим комитетом.

Согласие пациента. Пациент добровольно подписал информированное согласие на публикацию персональной медицинской информации в журнале «Гепатология и гастроэнтерология».

Сведения об авторах:

Ильченко Людмила Юрьевна, д-р мед. наук, профессор; Российский национальный исследовательский медицинский университет имени Н. И. Пирогова; e-mail: ilchenko-med@ yandex.ru ORCID:0000-0001-6029-1864

Федоров Илья Германович, канд. мед. наук, доц. Российский национальный исследовательский медицинский университет имени Н.И. Пирогова; e-mail: fig-med@yandex.ru; ORCID:0000-0003-1003-539X)

Тотолян Гаяне Гургеновна, канд. мед. наук, доц. Российский национальный исследовательский медицинский университет имени Н.И. Пирогова; e-mail: tgg03@mail.ru; ORCID:0000-0002-9922-5845),

Цветкова Анастасия Геннадьевна, Государственное бюджетное учреждение здравоохранения «Городская клиническая больница имени В.М. Буянова» Департамента здравоохранения города Москвы; e-mail: nastik.07@bk.ru; ORCID:0000-0002-5186-8251),

Гавриленко Екатерина Геннадиевна; Российский национальный исследовательский медицинский университет имени Н.И. Пирогова; e-mail: pchela39@gmail.com; ORCID:0000-0003-1079-1902

Миронов Константин Олегович, д-р мед. наук; Федеральное бюджетное учреждение науки «Центральный научно-исследовательский институт эпидемиологии» Роспотребнадзора; e-mail: mironov@pcr.ru; ORCID:0000-0001-8207-9215

Никитин Игорь Геннадиевич, д-р мед. наук, проф. Российский национальный исследовательский медицинский университет имени Н.И. Пирогова; e-mail: igor.nikitin.64@mail.ru; ORCID:0000-0003-1699-0881 gene regulation and interindividual variation of UDPglucuronosyltransferase activity in human small intestine. $J$ Biol Chem. 2000;275(46):36164-71. doi: 10.1074/jbc. M002180200.

12. Ebrahimi A, Rahim F. Crigler-Najiar Syndrome: Current Perspectives and the Application of Clinical Genetics. Endocr Metab Immune Disord Drug Targets. 2018;18(3):201-211. doi: 10.2174/1871530318666171213153130.

13. Mackenzie PI, Owens IS, Burchell B, Bock KW, Bairoch A, Bélanger A, Fournel-Gigleux S, Green M, Hum DW, lyanagi $T$, Lancet $D$, Louisot $P$, Magdalou J, Chowdhury JR, Ritter JK, Schachter H, Tephly TR, Tipton KF, Nebert DW. The UDP glycosyltransferase gene superfamily: recommended nomenclature update based on evolutionary divergence. Pharmacogenetics. 1997;7(4):255-69. doi: 10.1097/00008571-199708000-00001.

14. Zheng B, Hu G, Yu J, Liu Z. Crigler-Najjar syndrome type II in a Chinese boy resulting from three mutations in the bilirubin uridine 5'-diphosphate-glucuronosyltransferase (UGT1A1) gene and a family genetic analysis. BMC Pediatr. 2014;14:267. doi: 10.1186/1471-2431-14-267.

15. Takeuchi K, Kobayashi Y, Tamaki S, Ishihara T, Maruo Y, Araki J, Mifuji R, Itani T, Kuroda M, Sato H, Kaito M, Adachi Y. Genetic polymorphisms of bilirubin uridine diphosphate-glucuronosyltransferase gene in Japanese patients with Crigler-Najjar syndrome or Gilbert's syndrome as well as in healthy Japanese subjects. J Gastroenterol Hepatol. 2004;19(9):1023-8. doi: 10.1111/j.14401746.2004.03370.x

Conflict of interest. The authors declare no conflict of interest.

Financing. The study was performed without external funding.

Conformity with the principles of ethics. The study was approved by the local ethics committee.

Informed consent statement. The patient has voluntarily signed his informed consent for the publication of his personal medical information in the journal of Hepatology and Gastroenterolodgy.

Information about authors:

Ilchenko Lyudmila Yu., PhD, MD (Medicine), professor; Pirogov Russian national research medical university; e-mail: ilchenko-med@yandex.ru.

Fedorov Iliya G. PhD (Medicine), Associate Professor; Pirogov Russian national research medical university; e-mail: fig-med@yandex.ru; ORCID:0000-0003-1003-539X)

Totolyan Gayane G. PhD (Medicine), Associate Professor; Pirogov Russian national research medical university; e-mail: tgg03@mail.ru; ORCID:0000-0002-9922-5845),

Tsvetkova Anastasiya G. Moscow City Clinical Hospital after V.M. Buyanov; e-mail: nastik.07@bk.ru; ORCID:0000-0002-5186-8251),

Gavrilenko Ekaterina G. Pirogov Russian national research medical university; e-mail: pchela39@gmail.com; ORCID: 0000-0003-1079-1902

Mironov Konstantin O. PhD, MD (Medicine); Federal Budget Institution of Science "Central Research Institute of Epidemiology" of The Federal Service on Customers' Rights Protection and Human Well-being Surveillance; e-mail: mironov@pcr.ru; ORCID:0000-0001-8207-9215

Nikitin Igor G. PhD, MD (Medicine), Professor; Pirogov Russian national research medical university; e-mail: igor.nikitin.64@mail.ru; ORCID:0000-0003-1699-0881 